\title{
Bruggen bouwen tussen talen en culturen: actuele toestand van het onderzoek van sociaal tolken in de wereld en in Slowakije
}

\author{
Building bridges between languages and cultures: actual state of \\ the research in community interpreting in the world and in Slovakia
}

Michal Homola

\begin{abstract}
This study deals with actual trends and developments in the research of community interpreting in the global, but also in local context. In the general introduction we try to define the term community interpreting according to the latest trends in this field. Our goal is to set some basic features, which can help to create a universal definition of the actual content of the term community interpreting. In the next part we concentrate on the development in the world and try to analyse the most significant research projects in the field. Finally, we show a short overview of the most important initiatives in the local context en introduce our own starting research, which will be focussed on the analysis of the actual state of community interpreting in Slovakia.
\end{abstract}

\section{Keywords}

Community interpreting, global research, local context, health care, legal context 


\section{Afbakening van het begrip}

Voordat wij ons met de actuele stand van zaken bij het onderzoek op dit gebied zullen bezighouden, vinden wij het belangrijk om het begrip sociaal tolken preciezer af te bakenen. Aangezien er relatief grote onenigheden bestaan onder vertaal- en tolkwetenschappers over de inhoud en de breedte van het begrip in kwestie, is het een bijzonder moeilijke taak om een algemene en universele definitie hiervan vast te leggen. Wij proberen echter tenminste enkele basispunten vast te stellen die wij als algemeen geldig zouden kunnen beschouwen.

Het gegeven gebied van de vertaal- en tolkwetenschap begon zich pas in de jaren 70 af te tekenen. Volgens Chesher (1997) verwees de term community interpreting toen naar het tolken gerealiseerd onder leden van een minderheidsgemeenschap, in tegenstelling tot het conferentietolken dat zich meestal onder deelnemers van een internationale conferentie afspeelt.

Het model van een eenvoudige dichotomie van sociaal en conferentietolken is volgens ons niet meer actueel. De grenzen tussen deze subdisciplines kunnen niet eenduidig vastgelegd worden en er ontstaan qua context ook andere soorten tolken zoals business of diplomatiek tolken.

Community interpreting was oorspronkelijk alleen een complementaire subdiscipline naast conference interpreting. Vereenvoudigd kan men stellen dat de afbakening van dit begrip uit de trend van systematisering van de vertaal- en tolkwetenschap voortvloeide en uit de behoefte aan een overkoepelende subdiscipline die het reeds bestaande conferentietolken zou aanvullen. Tegenwoordig is het sociaal tolken zeker een gerespecteerd onderdeel van het systeem van vertaal- en tolkwetenschap, niet alleen ten opzichte van de omvang en kwaliteit van het gerealiseerde onderzoek, maar ook met betrekking tot de geleidelijke institutionalisering en professionalisering van deze subdiscipline.

\section{Kenmerken van sociaal tolken}

Een van de inherente kenmerken van het sociaal tolken is ongetwijfeld het intrasociale karakter ervan (zie Pöchhacker, 2004, pp. 14-15). Het sociaal tolken wordt binnen een bepaald maatschappelijk systeem gerealiseerd en de hoofdfunctie ervan is om de communicatie tussen openbare instellingen en zulke personen te bemiddelen die de officiële taal van de staat niet op een voldoend niveau beheersen. Het kan om etnische minderheden of migranten gaan, maar ook om gewone toeristen of personen met een ernstige, voornamelijk auditieve beperking. ${ }^{1}$

In tegenstelling hiermee staat het begrip conferentietolken, waarbij de communicatie tussen leden van meerdere maatschappelijke systemen, meestal binnen een conferentie of andere vergadering wordt bemiddeld. Een soortgelijk voorbeeld is ook het business of diplomatieke tolken. 
De tweede inherente kenmerk van sociaal tolken is de asymetrische relatie tussen de communicatoren. Aan de ene kant staat een vertegenwoordiger van een openbare instelling (rechtbank, ziekenhuis, school enz.) en aan de andere kant een anderstalige persoon (lid van een etnische minderheid, vluchteling,een economische migrant, expat, enz.). Volgens Rudvin (2005, pp. 163-164) zou de asymetrie tussen de communicatoren ook zonder inachtneming van taal- of culturele verschillen duidelijk zichtbaar zijn. Zij vermeldt vijf factoren die de asymetrie stimuleren:

De eerste factor is het feit dat de anderstalige persoon van een bepaalde dienst van de openbare instelling gebruik wil maken en de vertegenwoordiger van de instelling deze dienst kan verlenen of weigeren. Andere factoren zijn de positie van een expert / leek in de gegeven problematiek, het maatschappelijke statuut van de communicatoren, de kwetsbaarheid van de aanvrager en het karakter van de verleende dienst. Deze factoren zijn algemeen geldig, maar in het kader van de context van het sociaal tolken moet men hieraan nog de factor van een meerderheids- / minderheidscultuur en meerderheids- / minderheidstaal toevoegen. Daardoor wordt de asymetrie tussen de communicerende partijen alleen maar vergroot. Als wij in dit verband het sociaal tolken met conferentieof businesstolken vergelijken, beseffen wij dat bij de andere soorten tolken de asymetrie over het algemeen veel kleiner is (deelnemers van een conferentie, businesspartners enz.).

Met de asymetrische relatie tussen de communicatoren hangt ook het karakter van de communicatieve situatie nauw samen. In tegenstelling tot het conferentietolken verloopt het sociaal tolken praktisch altijd in beide richtingen. Het gaat meestal om een dialogische communicatie die in de regel niet vooraf gepland en georganiseerd is (Jacobsen, 2009, pp. 156). De getolkte communicatie wordt vaak door expressieve taalmiddelen gekenmerkt en de sociale tolk wordt met emotionele en spontane uitingen en soms ook met verbale aanvallen geconfronteerd. De communicatoren respecteren de rol van de tolk vaak niet wat zijn werk nog moeilijker maakt. De tolk wordt daardoor gedwongen snel te reageren en ad hoc oplossingen te gebruiken.

\section{Actuele trends in het onderzoek van het sociaal tolken in de wereld}

Aan het begin van dit hoofdstuk proberen wij de problematiek van sociaal tolken in een bredere context van vertaal- en tolkwetenschap in te passen. In het algemeen kunnen wij constateren dat terwijl onderzoek naar het vertalen overwegend op het object van het vertaalproces (bron- / doeltekst) wordt verricht, wordt er bij het onderzoek op het terrein van het tolken in hogere mate ook het subject van het proces (de tolk) geanalyseerd. Er wordt bijvoorbeeld ook gekeken naar de wijze, waarop bepaalde individuele eigenschappen van een concrete tolk de uiteindelijke resultaten van het tolkproces kunnen beïnvloeden.

Als wij het conferentie- en sociaal tolken vergelijken, stellen wij vast dat er ook relatief grote verschillen bestaan in het onderzoek tussen deze twee gebieden. In de context 
van het conferentietolken vestigen the wetenschappers meer aandacht op verschillende cognitieve, neurolinguistische en neurofysiologische aspecten (het geheugen of anticipatievermogen van de tolk, maar ook op het concrete tolkproces (het aantal autocorrecties, décalage enz.). Op het terrein van sociaal tolken gaat de aandacht van het onderzoek meer uit naar de perceptie van de rol van de tolk en van andere deelnemers in het kader van het tolkproces, ethische problemen, verwachtingen van de klanten of professionaliteit en neutraliteit van de tolken (Jacobsen, 2009, pp. 155-156).

Volgens Rudvin (2006, pp. 31) heeft het onderzoek in sociaal tolken zich geleidelijk vanuit de oorspronkelijke prescriptieve aanpak ontwikkeld, waarbij dezelfde criteria op conferentie- en sociaal tolken werden toegepast, en vervolgens een meer realistische, alomvattende aanpak die de positie van dit soort tolken in het complexe maatschappelijke systeem respecteert.

Vargas-Urpi (2012, pp. 50) benadrukt het interdisciplinaire karakter van het onderzoek in sociaal tolken. Tegenwoordig is het niet meer alleen het object van vertaal- en tolkwetenschap, maar wordt onderzoek naar sociaal tolken in hoge mate ook door andere disciplines beïnvloed, zoals toegepaste taalkunde, sociologie, antropologie, psychologie of communicatietheorie.

In verband met het onderzoek van sociaal tolken is het nodig om de internationale vereniging Critical Link International te vermelden, waarin professionele tolken en theoretici uit de hele wereld samenwerken die op het terrein van sociaal tolken actief zijn. Het netwerk Critical Link werd in het jaar 1992 aan de Universiteit van Ottawa opgericht met het doel om de eerste internationale conferentie over sociaal tolken te organiseren. Deze vond in 1995 in de Canadeze stad Orillia plaats en volgens Hertog en Van der Veen (2006, pp. 11) begon men juist op deze conferentie community interpreting als een aparte subdiscipline van de vertaal- en tolkwetenschap te onderscheiden².

\section{Sociaal tolken in de gezondheidssector}

De sector van gezondheidszorg is een van de contexten, waarin de grootste omvang van het onderzoek van sociaal tolken werd gerealiseerd. Het gaat om een uiterst divers en complex gebied, dus ook het gerelateerde onderzoek wordt op verschillende thema's toegespitst. Als wij echter een gezamelijk onderzoeksthema zouden moeten specificeren, zouden wij waarschijnlijk het thema van kwaliteit op verschillende niveaus kiezen: kwaliteit van de vertolking, kwaliteit van de gehele prestatie, kwaliteit van de communicatie, kwaliteit van de gezondheidszorg enz. (zie Pöchhacker, 2006, pp. 155).

Een specifiek aspect van deze context is de hoge mate van gevoeligheid en vertrouwelijkheid van de gegevens, waarmee er bij het onderzoek wordt gewerkt. Het gaat om uiterst persoonlijke gegevens van patiënten die tijdens getolkte consultaties van hun arts

2 De CLI-conferenties worden sinds 1995 regelmatig, om de drie jaar georganiseerd en vormen een gerespecteerd platform voor presentatie van de laatste resultaten op het gebied van sociaal tolken. Meer over de activiteiten van het CLI-netwerk kunt $\mathrm{u}$ on de officiële website vinden: https://criticallink.org/ 
worden vermeld. Daarom is het hier heel belangrijk om de toegang tot en de manipulatie met deze gegevens streng te controleren en te regelen.

De eerste publicaties over het tolken in de gezondheidssector gaan terug tot in de jaren 60 en 70 van de 20-ste eeuw en werden meestal in de Verenigde Staten gepubliceerd. In tegenstelling tot vandaag, waren hun auteurs doorgaans geen vertaal- en tolkwetenschappers of taalkundigen, maar artsen en verplegers zelf die met het probleem van taalbarrières in de medische zorg werden geconfronteerd (zie Richie, 1964, Bloom, Hanson, Frires en South, 1968 of Marcos, 1979).

Als een baanbreker in het onderzoek rond sociaal tolken in de context van gezondheidszorg in Europa kunnen wij twijfelloos Cecilia Wadensjö beschouwen. Met behulp van discoursanalyse onderzocht zij geluidopnames van medische consultaties uit meerdere Zweedse ziekenhuizen en de bevindingen interpreteerde zij op basis van de dialogische theorie van taal en communicatie van Michail M. Bachtin. Haar bekendste werk Interpreting as interaction (1998) hoort tot nu toe tot de meest citeerde publicaties die zich met de problematiek van sociaal tolken in gezondheidszorg bezig houden.

Meerdere auteurs wijzen in hun publicaties op de problematiek van gebruik van ongetrainde, niet-professionele tolken binnen gezondheidssector. B. Meyer analyseert potentiële medische complicaties die door onjuiste vertolking kunnen ontstaan. Hij benadrukt het nut van professionalisering van tolken binnen de gezondheidssector (zie Meyer, Bührig, 2014 en Meyer, Thiesemann, 2018). Voor potentiële risico's van werken met ongetrainde tolken, vooral familieleden, waarschuwt ook J. Cambridge. Hij vestigt zijn aandacht op semantische verschuivingen en weglatingen bij het tolken van medische consultaties door ongekwalificeerde tolken (zie Cambridge, 2002).

Cambridge houdt zich in zijn recentste publicaties ook bezig met een ander actueel thema, met name tolken voor patiënten met psychiatrische aandoeningen (zie Cambridge, 2018). Volgens hem worden juist deze uiterst kwetsbare patiënten door onvoldoende toegang tot medische zorg in hun moedertaal aan een enorm risico blootgesteld. Met deze problematiek houdt zich ook de Nederlandse psychotherapeut H. Bot bezig (zie Bot, 2005) die op basis van een corpus van videoopnames van medische consultaties een theoretisch kader voor het tolken voor psychiatrische patiënten heeft ontworpen.

Tot de belangrijkste experten op het gebied van tolken in de medische context hoort ook A. Bischoff die in zijn talrijke studies het niveau van tolkdiensten in Europa, maar vooral in Zwitserland in de kaart brengt en wijst op de beperkte toegang van anderstaligen tot medische zorg (zie Bischoff, 2006 en Bischoff, Hudelson, 2010).

Wat de VS betreft, moeten wij in elk geval Claudia Angelelli vermelden die de problematiek van sociaal tolken in medische zorg op basis van grootschalige corpora van gegevens uit medische instellingen van California voornamelijk vanuit psychometrisch en etnografisch perspectief analyseert (zie Angelelli, 2018 en 2014). Haar monografie Healthcare Interpreting Explained (2019) kunnen wij als een potentieel didactisch materiaal voor studententolken beschouwen.

Wij hebben hier vanwege het korte bestek van deze bijdrage alleen enkele van de belangrijkste publicaties vermeld die zich bezighouden met tolken in de gezondheidssector. 
Voor een meer gedetailleerd overzicht van gerelateerde studies en onderzoeksmaterialen zie bijv. Pöchhacker (2006), Jacobs (2003), Hale (2007) of Vargas-Urpi (2012).

\section{Tolken in het juridisch discours}

Het juridische discours hoort naast de gezondheidssector tot de meest onderzochte en bediscussieerde contexten van sociaal tolken. Hale (2007, p. 90) wijst op enkele redenen, waarom juist deze context voor de teoretici zo interessant is: Enerzijds heeft dit te maken met een relatief goede toegankelijkheid van opnames en andere materialen uit de processen of verhoren en anderzijds gaat het natuurlijk om een gebied dat relatief veel aandacht van het publiek en van media aantrekt. De derde reden is het consistente karakter van het juridische discours wat een meer effectieve categorisatie en analyse van gezamelde gegevens mogelijk maakt (zeker bijvoorbeeld in vergelijking met de medische context).

Thematisch worden de studies op dit gebied voornamelijk gericht op de analyse van het specifieke discours van rechtsgedingen en politieverhoren en de invloed van dit soort discours op het tolkproces., Maar ook de problematiek van de rol van de tolk binnen een proces of verhoor en de hiermee samenhangende training en professionalisering van juridisch tolken wordt geanalyseerd.

$\mathrm{Al}$ in de jaren 70 begon men met het analyseren met de taalkundige aspecten in het kader van gerechtelijke processen. Sinds de jaren 90 vestigde men in deze context meer aandacht op de problematiek van bilinguale communicatie via een tolk. Hierbij heeft de oprichting van het internationale tijdschrift Forensic Linguistics een belangrijke rol gespeeld, waarin meerdere studies over dit thema werden gepubliceerd.

Een groot aantal onderzoeksprojecten op dit terrein werden gebaseerd op corpusanalyse van opnames en andere materialen uit de processen. In deze samenhang moeten wij vooral twee auteurs vermelden: De eerste is Susan Berk-Seligson. In haar publicaties interpreteert zij de uitkomsten van een grootschalig onderzoek dat aan het einde van de 20-ste eeuw aan verschillende rechtbanken in de VS werd gerealiseerd (zie Berk-Seligson, 1990, 2002, 2017). Een gelijksoortig onderzoek in het kader van het Australische rechtssysteem heeft ook Sandra Beatriz Hale geanalyseerd (zie Hale, 2004). Beide auteurs hebben behalve de methodologie van discoursanalyse ook van etnografische methodes gebruik gemaakt en beiden hebben uit hun analyse een gezamenlijke conclusie getrokken; met name dat de deelnemers van het proces een bepaald deel van hun verantwoordelijkheid aan de capaciteiten van de tolk overdragen, waardoor op hem veel grotere eisen worden gesteld dan alleen de transpositie van uitgesproken informatie naar de doeltaal. Daarom benadrukken zij de belangrijkheid van adequate opleiding voor de juridische tolken.

Meerdere auteurs vestigden hun aandacht op de rol van de tolk binnen het proces. Mason en Stewart (2001) probeerden op basis van dialogische analyse vast te stellen, of de letterlijke vertolking, die door vele rechters wordt vereist, tot semantische of functionele verschuivingen kan leiden. Martin a Ortega-Heráez (2009) hebben een grootschalig onderzoek onder Spaanse juridische tolken gerealiseerd en zijn tot conclusie gekomen 
dat de meeste tolken zichzelf niet alleen als taalbemiddelaars, maar ook als facilitatoren van de communicatie waarnemen. Kinnunen (2010) wijst op de afwezigheid van een eenduidige definitie van de rol van de tolk binnen het proces en op daarmee samenhangende negatieve gevolgen voor de kwaliteit van het tolken. Is het de functie van een juridische tolk alleen om de inhoud van een gesproken tekst naar de doeltaal letterlijk over te dragen of kan hij ook de positie van een cultuurbemiddelaar innemen?

Een belangrijke rol speelt ook de problematiek van evaluering van de kwaliteit van het tolken. Hiervoor werd ook een internationaal project, namelijk Qualitas: Assessing LI Quality through Testing and Certification opgericht. Het hoofddoel van dit project was om een controlemechanisme van de kwaliteit in het kader van juridisch tolken te creëren (zie Giambruno, 2016).

In de laatste jaren wordt ook een steeds grotere nadruk gelegd op het onderzoek van technologische aspecten van het tolken in het kader van politieonderzoek. Op de analyse van kwaliteit en technologische voorwaarden van het afstandstolken werd het internationale project AVIDICUS gericht, waarin de kwaliteit van het tolkproces bij het afstandstolken met het directe tolken (op plaats) werd vergeleken.

Een groeiend aantal onderzoeksprojecten wordt in de laatste tijd ook toegespitst op de context van het tolken in het kader van een asielprocedure. Dit komt vooral door de vluchtelingencrisis in Europa, maar ook economische migratie naar de meest ontwikkelde landen. Juist in deze context kunnen wij waarschijnlijk over een van de meest asymetrische relaties tussen de aanvragers en de vertegenwoordigers van de staatsinstellingen spreken. In vele landen gaat het om een erg controversiële problematiek en het statuut van een migrant wordt met negatieve vooroordelen verbonden. De tolk wordt in deze context met emotionele situaties geconfronteerd en er wordt van hem een hoge mate van professionaliteit vereist. Een onjuiste transpositie kan het resultaat van de procedure sterk beïnvloeden wat volgens Pöllabauer (2012, pp. 144) in enkele gevallen praktisch een doodsvonnis kan betekenen.

Sonja Pöllabauer behoort tegenwoordig tot de meest gerespecteerde onderzoekers die zich met deze problematiek bezighouden. In haar proefschrift heeft zij opnames van tientallen asielprocedures in Oostenrijk geanalyseerd en een ernstig gebrek aan specifieke voorbereiding van de tolken op dit gebied geconstateerd (zie Pöllabauer, 2006). Jimenez Ivars en León-Pinilla (2018) hebben een onderzoek in verschillende asielcentra in Spanje gerealiseerd en wijzen op niet-objectieve eisen die door asielaanvrager op het werk van de tolk worden gesteld. Meerdere onderzoeks- en opleidingsprojecten op dit terrein worden ook door het Hoge Commissariaat voor de Vluchtelingen georganiseerd. ${ }^{3}$

Dit was alleen een kort overzicht van de belangrijkste trends in het onderzoek in het kader van het tolken in juridische context. Gedetailleerde informatie over deze problematiek kunt u bijv. Bij Hale (2006, 2007) vinden die niet alleen de richtinggevende activiteiten in het onderzoek samenvat, maar ook relevante en actuele problemen van juridisch tolken analyseert. Methodologische aspecten van het onderzoek in deze context worden door Biel, Engberg, Martín Ruano en Sosoni (2019) besproken. Hertog 
(2015) biedt een systematisch overzicht van het onderzoek van juridisch tolken in de EU aan het begin van de 21-ste eeuw aan. Monteoliva-Garcia (2018) vat in haar publicatie de belangrijkste onderzoeksprojecten van de periode tussen 2008 en 2017 samen.

\section{Onderzoek van sociaal tolken in Slowaakse context}

Over het algemeen kunnen wij constateren dat het onderzoek van sociaal tolken in de Slowaakse context zich pas vanaf het begin van deze eeuw begon te ontwikkelen. In de recentste periode hebben wij enkele interessante initiatieven gemerkt die een vooruitgang op dit terrein hebben gebracht. De meeste hebben zich in de belangrijke academische centra gevormd, waar men zich met de problematiek van vertaal- en tolkwetenschap bezighoudt.

Een van zulke centra is in elk geval de Filosofische Faculteit van Universiteit van Prešov, waar onder leiding van Jarmila Opalková vanaf het jaar 2011 het project Sociaal tolken in de nieuwe maatschappelijke situatie in Slowakije werd gerealiseerd. Het project werd voornamelijk toegespitst op opleiding van toekomstige sociale tolken en op het creeren van actueel terminologisch materiaal voor deze context. De hoofdimpuls voor dit project was de afwezigheid van hoogwaardige didactische materialen voor een opleiding rond sociaal tolken in de Slowaakse context. De belangrijkste uitkomst van dit initiatief was de trilogie van het leerboek, oefenboek en terminologisch woordenboek van sociaal tolken (zie Opalková, 2013a, 2013b, 2013c).

Een volgend belangrijk centrum van het onderzoek naar sociaal tolken is de Filosofische Faculteit van Comenius Universiteit in Bratislava. Hier wordt in samenwerking met de universiteiten van Olomouc, Wroclaw en met de Erasmus Universiteit in Brussel het project Professional Accessible Community Interpreting (PACI) gerealiseerd. De functie van coordinator van het project wordt door Marketa Štefková van de afdeling germanistiek, neerlandistiek en scandinavistiek van de Comenius Universiteit uitgeoefend. Het hoofddoel van het PACI-initiatief is om de voorbereiding van studenten vertalen en tolken op het werk binnen openbare instellingen te verbeteren door het creëren van een modern toegankelijk platform voor E-learningcursussen rond sociaal tolken. Het project wordt primair op centraal-Europese talen in combinatie met het Nederlands gericht, maar het doel is om een universeel platform, ook voor andere kleinere talen te vormen in de toekomst.

Aan de Filosofische Faculteit van Comenius Universiteit doceert ook Helena Tužinská die haar aandacht op het onderzoek van etnografische en mensenrechtelijke aspecten van sociaal tolken richt. Zij analyseert vooral de actuele situatie in Slowakie in context van het verlenen van tolkdiensten voor migranten. Haar publicatie Otázky opisu a prekla$d u$ (2010) kan als een algemeen handboek beschouwd worden, niet alleen voor vertalers of tolken, maar ook voor vertegenwoordigers van openbare instellingen of NGO's, waarin antropologische en etnografische perspectieven op het voeren van interviews met asielaanvragers worden toegepast. In de publicatie Komunikácia s cudzincami: právne dôsledky tlmočenia (2011) presenteert zij de resultaten van een comparatieve studie van de actuele toestand van verleende tolkdiensten voor migranten binnen openbare instel- 
lingen in de landen van V4 en in Oekraïne. Deze studie gaat verder uit van de nationale rapporten Practices in interviewing immigrants: legal implications.

Meerdere auteurs houden zich bezig met de problematiek van het tolken in de juridische context. Štefaňáková (2017) vergelijkt in haar studie de terminologie en structuur van het asielrecht in Slowakije en in Duitstalige landen. Ook zij benadrukt het nut van training en professionalisering van sociale tolken in Slowakije. Theoretische aspecten van juridisch tolken worden o.a. door Štefčík (2010), Guldanová (2010) of Sovinec (2017) geanaliseerd. Met dit gebied houdt zich ook het tijdschrift Kontexty súdneho prekladu a tlmočenia bezig dat één keer per jaar aan de Comenius Universiteit verschijnt.

Een interessante bijdrage in de context van sociaal tolken wordt gebracht door Štefková en Bossaert (2019). De auteurs vergelijken in hun artikel de historische ontwikkeling en actuele situatie op dit gebied in Slowakije en in België. België gebruiken zij hierbij als een goed referentievoorbeeld met een hoge graad van institutionalisering en professionalisering van sociaal tolken. Zij wijzen op een gebrek aan standaardisering in regeling van het verlenen van tolkdiensten binnen de openbare sector in Slowakije en op relatief grote invloed van politieke macht van concrete minderheden op het niveau van verleende tolkdiensten.

\section{Korte voorstelling van ons eigen onderzoek}

Om een algemene conclusie te trekken, kunnen wij constateren dat het onderzoek op het gebied van sociaal tolken in de wereld een dynamische ontwikkeling in de laatste 30 jaar heeft doorgemaakt. Er zijn talrijke studies beschikbaar die dit thema vanuit verschillende perspectieven analyseren en bijdragen uit allerlei wetenschappelijke disciplines opleveren. Ook in de Slowaakse context begon men zich met deze problematiek bezig te houden. Het onderzoek beperkt zich echter tot enkele kleine academische centra en wij kunnen hier een absentie van een meer systematische vertaal- en tolkwetenschappelijke aanpak constateren. Door ons eigen onderzoek, dat wij in het kader van ons proefschrift gaan maken, willen wij de actuele situatie binnen de openbare sector in Slowakije in kaart brengen, maar vooral bijdragen aan de verbetering van verleende tolkdiensten en hun toegankelijkheid.

Het onderzoek wordt bij verschillende openbare instellingen gerealiseerd (o.a. instellingen voor migranten en asielzoekers, vreemdelingenpolitie, grote ziekenhuizen, scholen die ervaringen hebben met etnische minderheden of kinderen van migranten, overheidsinstellingen enz.). Bij het onderzoek grijpen wij naar kwalitatieve methodes, vooral mondelinge diepgaande interviews met vertegenwoordigers van de gekozen publieke instellingen. We proberen door middel van deze interviews antwoorden te zoeken op de volgende vragen:

1. Voor wie wordt er binnen de openbare sector getolkt en wat is het niveau van toegankelijkheid van de tolkdiensten?

2. Door wie worden de tolken gekozen en aan welke professionele criteria moeten zij voldoen?

3. Uit welke middelen worden de tolkdiensten gefinancierd? 
4. Op welke manier is de evaluering van de tolkdiensten gerealiseerd en hebben de communicatoren een mogelijkheid om feedback te krijgen?

5. Op welke manier worden toekomstige sociale tolken opgeleid?

6. Bestaan er mogelijkheden voor sociaal tolken, maar ook vertegenwoordigers van openbare instellingen om verder opgeleid en getraind te worden?

Op basis van de informatie die wij door middel van vragenlijsten of interviews met vertegenwoordigers van openbare instellingen, maar ook van etnische minderheden krijgen, zullen wij proberen de actuele situatie te analyseren en de belangrijkste problemen te benoemen. Ons hoofddoel is naar potentiële oplossingen en verbeteringen te zoeken die door vertaal- en tolkwetenschap kunnen worden aangeboden. Daarbij zullen wij van positieve voorbeelden uit buitenland uitgaan, dus van die landen die op het gebied van effectieve verlening van tolkdiensten binnen openbare instellingen veel ervaring hebben en succesvol zijn (bijv. België, Nederland, Zwitserland, Oostenrijk of de Scandinavische landen). Wij zullen namelijk de huidige situatiein verlening van tolkdiensten door publieke instellingen in Slowakije met concrete ontwikkelingsfasen in de bovengenoemde landen vergelijken en naar mogelijke inspirerende oplossingen en maatregelen zoeken die naar verbetering van de kwaliteit van deze diensten in buitenland hebben geleid.

\section{Gebruikte literatuur}

Angelelli, Claudia. V. (2014). Interpreting in the healthcare setting: access in cross-linguistic communication. In H. E. Hamilton en S. Chou (Eds.), The Routledge Handbook of Language and Health Communication, (pp.. 573-585). London / New Yourk: Routledge.

Angelelli, Claudia. V. (2018). Can ethnographic findings become corpus-studies data? A researcher's ethical, practical and scientific dilemmas. The Interpreters' Newsletter, no. 22, 1-15.

Angelelli, Claudia. V. (Ed.). (2019). Healthcare Interpreting Explained. London, New York: Routledge.

Berk-Seligson, Susan. (1990 / 2002 / 2017). The bilingual courtroom: Court interpreters in the judicial process. Chicago: The University of Chicago Press.

Biel, Łucja., Engberg, J., Martín Ruano, R. en Sosoni, V. (Eds.). (2019). Research Methods in Legal Translation and Interpreting: Crossing Methodological Boundaries. London, New York: Routledge.

Bischoff, A. (2006). Caring for migrant and minority patients in European hospitals: A review of effective interventions. Neuchãtel/Basel: Swiss Forum for Migration and Population Studies.

Bischoff, A. en Hudelson, P. (2010). Communicating With Foreign Language-Speaking Patients: Is Access to Professional Interpreters Enough?. Journal of Travel Medicine, vol. 17, no. 1, 15-20.

Bloom, M. A., Hanson, H. Cw., Frires, G. en South, V. (1966). "The use of interpreters in interviewing". Mental Hygiene no. 50, 214-217.

Bot, H. (Ed.). (2005). Dialogue Interpreting in Mental Health. Amsterdam, New York: Rodopi.

Cambridge, J. (2002). Interlocutor roles and the pressures on interpreters. In: C. Valero-Garcés en G. Mancho-Barés (Eds.), Community interpreting and translating: new needs for new realities (pp. 119-124). Madrid: Servicio de Publicaciones de la Universidad de Alcalá.

Cambridge, J., Singh, S. P. en Johnson, M. R. D. (2012). The need for measurable standards in mental health interpreting: a neglected area. The Psychiatrist, no. 36, 121-124. 
Giambruno, Cynthia (2016). Quality assessment and political will: a necessary symbiosis. Language and Law / Linguagem e Direito, vol. 3, no. 2, 116-134.

Guldanová, Zuzana (2010). Tlmočník versus prekladatel’ podl’a zákona o súdnych tlmočníkoch a prekladateloch. In Z. Guldanová (Ed.), Teória a prax súdneho prekladu a tlmočenia (s. 1223). Bratislava: Tlmočnícky ústav FIF UK.

Hale, Sandra. B. (2004). The Discourse of Court Interpreting. Amsterdam, Philadelphia: John Benjamins.

Hale, Sandra B. (2006). Themes and methodological issues in court interpreting research. In: Erik Hertog en Bart van der Veer (Eds.), Linguistica Antverpiensia: New Series 5 (pp. 205-228). Antwerpen: Hoger Instituut voor Vertalers en Tolken.

Hale, Sandra B. (2007). Community Interpreting. Hampshire : Palgrave MacMillan.

Hertog, Erik (2015). Looking back while going forward: 15 years of legal interpreting in the EU. TRANS: Revista de Traductología, vol. 19, no. 1, 15-31.

Hertog, Erik en van der Veer, Bart (2006). Taking Stock: Research and Methodology in Community Interpreting. In E. Hertog en B. van der Veen (Eds.), Linguistica Antverpiensia: New Series, 5 (pp. 11, 17). Antwerpen: Hoger Instituut voor Vertalers en Tolken.

Chesher, T. (1997). Rhetoric and reality: two decades of community interpreting and translating in Australia. In S. E. Carr, R. Roberts, A. Dufour en D. Steyn (Eds.), The Critical Link: Interpreters in the Community (pp. 277-89). Amsterdam, Philadelphia: John Benjamins.

Jacobs, E., Agger-Gupta, N., Chen, A. Hm, Piotrowsky, A. en Hardt, E. J. (2003). Language Barriers in Health Care Settings: An annotated bibliography of the research literature. Woodland Hills, CA: The California Endowment.

Jacobsen, B. (2009). The community interpreter: a question of role. Hermes - Journal of language and communication studies, no. 42, 155-166.

Jiménez-Ivars, A. en León-Pinilla, R. (2018). Interpreting in refugee contexts: A descriptive and qualitative study. Language \& Communication, vol. 60, $28-43$.

Kinnunen, T. (2010). Agency, activity and court interpreting. In T. Kinnunen, en K. Koskinen (Eds.), Translators' Agency: Tampere Studies in Language, Translation and Culture, series B 4 (pp. 126-164). Tampere: Tampere University Press,.

Marcos, L. R. (1979). "Effects of interpreters on the evaluation of psychopathology in non-Englishspeaking patients”. American Journal of Psychiatry, vol. 136(2), 171-174.

Martín, A. en Ortega-Herráez, J. M. (2009). Court interpreters' self perception: A Spanish Case Study. In R. De Pedro-Ricoy, I. Pérez en C. Wilson (Eds.), Interpreting and Translating in Public Service Settings (pp. 141-155). London, New York: Routledge.

Mason, I., Stewart, M. (2001). Interactional Pragmatics, Face and the Dialogue Interpreter. In I. Mason (ed.), Triadic Exchanges: Studies in Dialogue Interpreting (pp. 51-70). Manchester: St. Jerome Publishing.

Meyer, B. en Bührig, K. (2014). Interpreting risks: Medical complications in interpreter-mediated doctor-patient communication. European Journal of Applied Linguistics Vol. 2, no. 2, 233-253.

Meyer, B. en Thiesemann, R. (2018). Bedeutung von Sprache im ärztlichen Aufklärungsgespräch. In R. Thiesemann (Ed.), Mit älteren Menschen kommunizieren (pp. 21-30). Stuttgart: Kolhammer.

Monteoliva-Garcia, E. (2018). The last ten years of legal interpreting research: A review of research in the field of legal interpreting. Language and Law / Linguagem e Direito, vol 5, no. 1, 38-61.

Opalková, Jarmila (2013a). Komunitné tlmočenie. Prešov: Acta Facultatis PUP.

Opalková, Jarmila (2013b). Cvičebnica (Komunitné tlmočenie). Prešov: Acta Facultatis PUP.

Opalková, Jarmila (2013c). Krátky slovník/Glosár komunitného tlmočníka. Prešov: Acta Facultatis PUP. 
Pöchhacker, Franz (2004). Introducing Interpreting Studies. London / New York: Routledge.

Pöchhacker, Franz (2006). Research and Methodology in Healthcare Interpreting. In Erik Hertog en Bart van der Veer (Eds.), Linguistica Antverpiensia: New Series 5 (s. 135-159). Antwerpen: Hoger Instituut voor Vertalers en Tolken.

Pöllabauer, Sonja (2006). "Translation culture" in interpreted asylum hearings. In A. Pym, M. Schlesinger en Z. Jettmarová (Eds.), Sociocultural Aspects of Translating and Interpreting (pp. 151-162). Amsterdam / Philadelphia: John Benjamins.

Pöllabauer, Sonja (2012). Community Interpreting. In C. A. Chapelle (Ed.), The Encyclopedia of Applied Linguistics. Oxford: Blackwell Publishing Ltd.

Richie, J. (1964). Using an interpreter effectively. Nursing News, vol. 12, 27-29.

Rudvin, Mette (2005). Power behind discourse and power in discourse in community interpreting: the effect of institutional power asymmetry on interpreter strategies. Revista Canaria de Estudios Ingleses, no. 51, 159-179.

Rudvin, Mette (2006). The Cultural Turn in Community Interpreting: A Brief Analysis of Epistemological Developments in Community Interpreting Literature in the Light of Paradigm Changes in the Humanities. In E. Hertog en B. van der Veen (Eds.), Linguistica Antverpiensia: New Series 5 (pp. 21-41). Antwerpen: Hoger Instituut voor Vertalers en Tolken.

Sovinec, Tomáš (2017). Besteht ein Unterschied zwischen der Praxeologie des Gerichtsdolmetschens und Konferenzdolmetschens?. Kontexty súdneho prekladu a tlmočenia, vol. 6, 181-192.

Štefaňáková, Jana (2017). Azylové konanie a vybrané pojmy azylového práva v nemecky hovoriacich krajinách a na Slovensku v komparácii. Kontexty súdneho prekladu a tlmočenia, vol. 6, 223-246.

Štefčík, Jozef (2010). Súdne tlmočenie. Nitra: Filozofická fakulta UKF.

Štefková, Marketa, Bossaert, Benjamin (2019). Equity, Quality and Vision - Comparative Analysis of the Practices of Public Service Translation and Interpreting in Slovakia and Flanders. Fitispos, International journal for Public service Interpreting and Translation, vol. 6, no. 1, 168-182.

Tužinská, Helena (2010). Otázky opisu a prekladu: Využitie poznatkov antropológie a etnografie vo vedení a tlmočení interview s imigrantmi. Bratislava: Stimul.

Tužinská, Helena (2011). Komunikácia s cudzincami: právne dôsledky tlmočenia. Porovnanie praktík v krajinách V4: v Pol'sku, v Mad’arsku, v Česku, na Slovensku a na Ukrajine. Bratislava: Liga za l'udské práva.

Vargas-Urpi, M. (2012). State of the Art in Community Interpreting Research: Mapping the Main Research Topics. Babel, vol. 58(1), 50-72.

Wadensjö, Cecilia (1998). Interpreting as Interaction. London, New York: Longman.

Michal Homola / michal.homola55@gmail.com

Comenius University in Bratislava

Department of German, Dutch en Scandinavian Studies

Gondova 2, 81499 Bratislava, SK

This work can be used in accordance with the Creative Commons BY-SA 4.0 International license terms and conditions (https://creativecommons.org/licenses/by-sa/4.0/legalcode). This does not apply to works or elements (such as image or photographs) that are used in the work under a contractual license or exception or limitation to relevant rights 